May - 2017

\title{
Talent Management Implementation at an Open Distance E-Learning Higher Educational Institution: The Views of Senior Line Managers
}

\author{
Barney Erasmus, Lynette Naidoo, and Pierre Joubert
}

University of South Africa

\begin{abstract}
The war for talent remains a challenge that many organisations face but more so for distance education institutions to deliver on its mandate to provide effective online academic offerings. The question that remains is: How can intellectual capital be managed effectively in order to recruit and retain talent that is necessary for success? This study was conducted at a mega open and distance learning institution, and this institution has identified talent management as one of the key strategic initiatives to ensure institutional strategic goal attainment and adopted an inclusive/developable talent approach as its framework. The aim of this article is to report on the perceptions of senior line managers regarding their experience with implementing the talent management strategy in their operational areas at the institution. This study adopted a qualitative approach and purposive sampling was used to select interviewees. The population group included chairpersons of 26 talent committees who are senior line managers and 11 of them were interviewed. Participants were of the opinion that policies and strategies do not always support the implementation of talent management in their respective environments. The findings show that although the university embraces the inclusive/developable talent approach in its strategy, the impact thereof is inhibited by a lack of methodological implementation, a lack of integration of supporting Human Resources policies with talent management, and insular line manager discernment.
\end{abstract}

Keywords: talent management, talent attraction, talent development, talent retention, inclusive talent approach

\section{Introduction}

A challenge that many organisations face, in particular higher education institutions, is how to attract and retain top talent (Van den Brink, Fruytier, \& Thunnissen, 2013). Organisations have entered a knowledge era, where learning rapidly and building competency and capability have become a prerequisite strategy 
for success (Mellahi \& Collings, 2010). Managing talent within an organisation has been identified as the lever capable of facilitating the attraction, development, and retention of the required skills and knowledge within the organisation through sound strategy, practices, and interventions (Schiemann, 2014). Although the focus of the majority of talent management (TM) reports and articles that have been published recently emanates from challenges experienced in the private sector and multinational companies (Thunnissen, Boselie, \& Fruytier, 2013), the same generic principles would apply to higher education open distance e-learning institutions although the context and unique challenges will be different (Metcalf, Rolfe, Stevens, \& Weale, 2005). According to Thunnissen (2016), a large number of publications have been produced by scholars on the topic of TM and talent but "scholarly peer-reviewed literature is lagging behind" (p. 57). Although there is great interest in the TM topic, very little is known about how successful TM initiatives are implemented if at all.

This study was conducted at the University of South Africa (Unisa), a mega distance higher education and the largest open distance e-learning institution in Africa (Mkhize, Mtsweni, \& Buthelezi, 2016; Ramdass \& Masithulela, 2016) and the longest standing dedicated distance education university in the world (Unisa, 2016). Apart from a strong research focus, the university, which employs 5000 staff, offers a variety of study choices to over 400,000 students. According to Bradley (2016), higher education institutions worldwide are facing strong competition for funding and students. Africa is also experiencing a brain drain (Mercy, 2011) and South Africa in particular is also competing for high-level human capital. Given this context and the strategic goals of the university, two initiatives were launched, namely; an Integrated Talent Management Strategy (ITMS) and a TM policy. In keeping with the aforementioned, this study aims to establish what really happens in practice by obtaining the views of senior line managers (Chairs of TM Committees) regarding their experience with the implementation of a TM strategy which is crucial to Unisa's success.

\section{Talent Delineated: A Review of the Literature}

Researchers are still trying to agree on a universally acceptable definition of TM (Lewis \& Heckman, 2006; Al, Cascio, \& Paauwe, 2014). However, a noteworthy feature of much of the existing TM literature is that it continues to focus on practices related to careers that are life-long in organisations. In this regard, Al, Cascio, and Paauwe (2014) conceptualise TM as "those activities and processes that enable identification of positions and talent pools that are critical to building and sustaining an organisation's competitive advantage" (p. 174). Lewis and Heckman (2006) argue that it is the lack of consistent or standardised definitions that have led to at least three different ways of interpreting TM in practice: the first interpretation is that TM is used to describe HR practices using new terminology; secondly, it may refer to succession planning practices; and thirdly, it may refer to the management of talented employees (in which case the term "talented" must be defined). Lewis and Heckman (2006) provide a critique of the literature on TM and state that the lack of consistent definitions appears to be the reason why there are so many ways of interpreting TM in practice which leads to possible confusion within the organisation.

Different views on talent seem to emanate from a focus on the future and current ability of employees for exemplary performance. The context within which contemporary TM research seems to take place involves mainly private sector organisations, multinationals, and organisations in the United States (US) 
context. The question can therefore be asked if the current concepts and assumptions in the TM literature related to this specific Anglo-Saxon context helps us to understand and explain TM issues in organisations in other contexts and geographies (Thunnissen et al., 2013).

Cappelli and Keller (2014) describe TM as "the process through which organisations anticipate and meet the needs for talent in strategic jobs" (p. 307). The authors continue to state that two debates emerged, namely; "inclusivity and exclusivity." Emphasis on employees as an integral part of an organisation's success was researched by Mishra (2008) where she argues that majority of employees within the organisation are part of a pool of ignored talent, and if suitably engaged, will be able to contribute a great deal to the organisation. In contrast to the aforementioned argument, Stahl et al.'s (2012) claim that "TM specifically involves attracting, selecting, developing and retaining high potential employees" (p. 38) and should not include all employees of any given organisation. In addition, Harter, Schmidt, and Keyes (2002) provide a compelling argument that highly engaged workers perform better than disengaged workers and this view is echoed by Van der Merwe, Basson, and Coetzee (2009) who refer to engaged employees finding more meaning in their work. Collings and Mellahi (2009) refer to the AMO-framework, where is it proposed that "employee performance is a function of the employee's ability (A), motivation (M) and opportunity (O) to perform" (p. 310) and these are the components that contribute to the TM system. Thunnissen, Boselie, and Fruytier (2013) propose that TM ought to provide talented, capable, and motivated employees the opportunity and space to develop themselves and to achieve high performance; this is aligned with Collings and Mellahi's (2009) reference to the AMO framework. These apparent contradictions begs the fundamental question whether the entire workforce is considered talent or only a limited group (Thunnissen, Boselie, \& Fruytier, 2015). Various perspectives of TM theory exist and it is in light of the differing views that Meyers and Van Woerkom (2014) developed a model of TM philosophies. The first area of TM theory that Meyers and Van Woerkom (2014) as well as Cappelli and Keller (2014) refer to is the issue of inclusivity and exclusivity. The exclusive talent approach is an elitist one which explains that a small percentage of employees are those who are high potentials, high performers, or critical in driving strategic objectives (Al et al. 2014; Meyers \& Van Woerkom, 2014). On the other hand, the inclusive approach (Meyers \& Van Woerkom, 2014), also referred to by Mishra (2008), promotes the perspective that all employees in the organisation's workforce are considered talent. The second area relates to whether talent is an innate (stable) or acquired (developable) construct (Meyers \& Van Woerkom, 2014).

In addressing the issues of exclusivity/inclusivity and stable/developable talent, Meyers and Van Woerkom (2014) refer to four TM philosophies namely, exclusive/stable, exclusive/developable, inclusive/stable, and inclusive/stable talent. The exclusive/stable talent philosophy takes on the elitist approach and considers elite groups as talent and the rest of the employees in the organisation are excluded (Galagan, 2008; McDonnel, 2011). The exclusive/developable talent philosophy (Meyers \& Van Woerkom, 2014) conceptualises talent as those employees who have potential and believe in the concept of latent talent that may only be realised through development (Amidon, 2005). The inclusive/stable talent philosophy focuses on employees' positive qualities where all employees are considered to have talents residing in them and it is through uncovering these positive qualities that the employee can contribute to the success of the organisation (Israelite, 2010). The afore mentioned reference to positive qualities of employees is aligned to (Gallardo-Gallardo, Dries, \& González-Cruz, 2013) strengths-based approach of TM and this perspective is embedded within the "talent as subject" approach and more 
specifically within the inclusive approach to TM. The inclusive/developable talent philosophy sees potential in every employee and this theory is that ordinary employees may be developed into extraordinary performers (Meyers \& Van Woerkom, 2014). The ambiguities regarding the definition, theoretical frameworks, and empirically-based recommendations are still prevalent, especially as it refers to implementation of TM in an organisation (Lewis \& Heckman, 2006). It should be noted that the inclusive and exclusive approaches to talent each have their own merits and challenges.

TM is not a stand-alone programme that resides solely within Human Resources (HR), but a concept that should be infused in the hearts and minds of all line managers and employees through creating and inculcating a talent mind-set across the organisation (Schiemann, 2014). In the absence of such a mindset, there is the danger of a lack of commitment. Stahl et al. (2012) argue that talent is pivotal to the operations of any organisation and this relates to business survival. This claim of talent being central to business survival and success is echoed by Collings and Melawi (2009) by stating that "the resources and capabilities that underpin firms' competitive advantage are directly tied to the capabilities of talented individuals who make up the firm's human capital pool" (p. 305). Ashton and Morton (2005) are also of the view that good TM significantly improves strategy execution and operational excellence.

Within the framework of this study, the inclusive/developable talent philosophy has been adopted because of the view that every employee has the potential to contribute towards the organisation's objectives and this capability may be developed (Meyers, Woerkom, \& Dries, 2013). Such development referred to may be possible through what Charles Jennings refers to as the 70-20-10 learning strategy, where it is argued that $70 \%$ of impactful learning emanates from experience (Jennings, 2013) where potential is developed into tangible experience. However, it must be noted that although this approach is adopted, a differentiated investment strategy is applied and this is a component borrowed from the exclusive/developmental approach. What this means is that although investment is made in all employees (inclusive), it is not equal investment that is applied in terms of time, effort, and money because of the unique needs of individuals that are prevalent, and this is where the exclusive approach is used.

\section{Research Methodology}

As indicated earlier, the aim on this study was to obtain the views of senior line managers (Chairs of TM Committees) regarding their experience with the implementation of a TM strategy. As a point of departure, a brief overview of two documents, namely; the ITMS and the TM policy are provided in this section followed by the research approach, target group identified, and a phased approach to conduct the research.

\section{Strategic Documents}

Two documents, namely; the ITMS and the TM policy provide the mandate and strategic direction for the TM initiative at the university.

The ITMS (Unisa, 2012) sets out the philosophy, purpose, and the strategic alignment of TM with the strategic goals of the university. This strategy rests on four pillars, namely; talent attraction, development, deployment, and retention, and provides the conceptual framework for the TM initiative. 
After the ITMS was consulted with all university stakeholders, including the trade unions, the university introduced a process to develop a TM policy.

The TM policy (Unisa, 2014) and associated procedures are aligned to the ITMS and aims to attract, develop, and retain talent in order to meet current and the changing future human resources needs. The purpose of the policy is to provide structured and systematic planning guidelines to ensure proper and seamless implementation of TM. Consequently, TM at the university involves a specific process that compares current talent in a department to the strategic needs of the institution in support of and in alignment with all human resources approved policies. The Departmental Talent Management and Employment Equity (EE) committees makes provision for Chairpersons of TM committees which need to be chaired by Executive Deans and Executive Directors and their responsibility is to identify the leadership and specialist development pools using identified criteria.

\section{Research Approach}

Exploratory research was used to gain insights into how TM was implemented at the university. This approach was adopted as exploratory research tends to address uncertainties and problems on which little or no previous research has been done (Brown, 2006). Towards this end, a qualitative methodology was adopted and data were collected by means of in-depth interviews by an experienced research psychologist among Chairpersons of TM committees in the University (senior line managers).

\section{Target Group}

The population group included chairs of the 26 TM Committees comprising senior line managers at the university and were considered suitable because they manage the daily operations of the organisation. Purposive sampling was used to select an equitable representation for its sample group within the university's complex environment, including the various campuses and regions. All 26 TM Committee chairs were invited to partake in an in-depth interview via telephone and e-mail. Eleven (two academics and nine support staff) consented to be interviewed at a convenient venue and time. All research protocols were observed in this study.

\section{Phased Approach to Collect Data and Conduct Interviews}

Phase one: Environmental scanning. The first phase comprised a literature review of relevant academic literature and the university's strategic TM documentation. The review of the academic literature was conducted aiming to explore different perspectives on TM with a view to adopt a particular TM philosophy that could provide a context for conducting the research. A discussion guide was developed consisting of themes and topics gleaned from the aforementioned research. To ensure reliability, the discussion guide was piloted with identified human resource specialists and line managers who did not form part of the sample group.

Phase two: Interviews with target group. The second phase involved in-depth interviews with the target group whereby verbatim responses to the main areas of discussion, namely perceived benefits of TM, TM interventions, shaping a talent mind-set, and the role of a talent manager, were contextualised against the insights from the academic literature, ITMS, and TM policy. It should be noted that the verbatim responses were digitally recorded with permission of the participants. 
Phase three: Finalising the main themes. The final phase consisted of analysing verbatim responses in terms of the underlying perceptions and attitudes expressed during the interviews. Although open coding was used in the analysis of the data, the identified themes assisted in providing a foundation for further analysis and interpretation whereby themes were juxtaposed against the insights acquired from phase two of the research. The main themes identified were, understanding TM, talent mind-set, and TM implementation inclusive of talent sourcing, development, deployment, and retention. A number of challenges relating to TM implementation were also identified but these were incorporated into the TM implementation main theme.

\section{Findings and Discussion}

Incorporated within this section are the findings of the in-depth interviews as well a discussion encapsulating relevant academic literature and the university's strategic TM documents. The main themes identified included understanding TM, talent mind-set, and TM implementation and are discussed below.

\section{Understanding TM}

The issue of understanding what TM is was a theme that was common to all participants and confirms the notion that no single perception exists for TM as it may be understood and applied differently. The subthemes focused on were valuing staff, awareness and inclusiveness. Comments from participants regarding the sub-theme valuing staff included the following: "the university should harness staff who have contributed towards the objectives set out by their departments"; "promote internal promotions without discriminating against outside applications"; "initial profiling of staff provides an opportunity to know and understand staff and their needs better"; "prepare people for succession"; and "recognise that individuals have different skills and strengths."

Most of the participants that were interviewed indicated that it is "critical for TM programmes and initiatives to be communicated and consulted with the organisation's key stakeholder groups to ensure cooperation and support." The participants expressed the need to be consulted and they hold the view that "the TM function is the responsibility of Human Resources." What is evident from this finding is that more consultation needs to take place across the university especially with line managers and that responsibility areas between HR and line managers should be clarified. What is significant about this finding is that line managers do not fully understand their specific role in the TM process. In other words, with more communication and consultation with line managers, the more effective the implementation and operationalisation of the TM strategy will be.

Despite different interpretations of talent, Lewis and Heckman's (2006) research and critique of TM reveal that most scholars (Al et al. 2014; Schiemann, 2014; Gallardo-Gallardo et al., 2013) agree on the impact of the context on the description of talent. Talent, according to Lewis and Heckman (2006) is not absolute - it is relative and subjective. It is also stated by Thunnissen et al. (2013) that the permutations of differentiating competencies and abilities differ according to the particular setting or situation and these contextual implications are reverberated by Al et al. (2014) and Stahl et al. (2012). At the university, the 
sentiment of Lewis and Heckman (2006) and Thunnissen et al. (2013) is shared, where the diversity in interpretation of TM is not seen as a barrier to the TM process; it is viewed rather as a dynamic that is associated with the concept of TM due to its contextual nature. However, in this article, it is argued that a common and shared understanding of TM and its related constructs and concepts need to be held within an organisation. This is the bedrock to the successful implementation of a talent programme with optimal impact.

\section{Talent Mind-Set}

The sub-themes embedded within the talent mind-set theme included employee engagement and an approach to TM and leadership. The theme also involves the attitudes of the line managers regarding using the principles of TM outlined in ITMS and TM policy.

It became clear during the interviews that participants made concerted efforts to "engage" with employees on the topic of TM. However, "time constraints and operational demands" were mentioned as impediments to fully engage with staff members. Some of the responses from the participants were: "It is important that we make space for engagement and communication with staff"; "personal engagements with staff is crucial"; "quarterly staff meetings should include matters of TM"; and "I haven't really engaged with staff specifically on this topic." Participants confirmed the importance of managers to have a passion for people development, although there is a general perception that not all managers foster a talent mind-set which is problematic. In this regard, Harter et al's (2002) assertion about highly engaged workers performing better than disengaged workers, which is measured through productivity, client satisfaction, and higher employee retention, relate to the findings of the in-depth interviews.

Meyers et al. (2013) indicate that talent identification should not be concerned with finding only the few employees within an organisation that are considered to be talented by their line managers, but rather it seeks to bring to light everyone's strengths so that they can be matched to adequate positions, tasks, and challenges. This reference to a strengths-based approach of TM, also referred to by (Gallardo-Gallardo et al., 2013) is supported in the university's ITMS which lays its foundation on a strengths-based approach to TM and states that the university will differentiate between various talent pools. In line with the university's talent pool approach, interviewees mentioned that "TM needs to differentiate between staff employees are at different levels with their careers as well as readiness to stretch; therefore not all interventions may be applicable to everyone; interventions must target the needs of individuals."

The university's ITMS states that part of the architecture of TM is to build a talent mind-set with line managers in order for them to provide the required talent leadership (Unisa, 2012). A concept related to the talent mind-set is the line manager's responsibility regarding the contribution he/she may make towards the employee's well-being and engagement with work. This is aligned with a concept borrowed from Psychology - the Pygmalion Effect which assumes that the expectations of a person on another are often fulfilled, and this may be demonstrated through managers' positive expectations of subordinates which serve to enhance their performance, and in turn, boosts productivity (Meyers et al., 2013). Meyers, et al. (2013) claim that organisations that consider all of their employees as talented might observe greater positive developments in the performance of their workforce. On the other hand, the negative Pygmalion Effect suggests that if a leader has negative expectations of employees, the result is a decrease in performance (Rosenthal, 1973). It is thus important for line managers to build and maintain a capable 
and committed workforce by assigning responsibilities to employees that they value and by further providing the relevant context whereby competence, autonomy, and relatedness are promoted.

The literature also provided examples of multiple stakeholders in the TM process. According to Thunnissen et al. (2013) and $\mathrm{Al}$ et al. (2014), line managers as one of the stakeholders have a responsibility to operationalise the TM strategy, and this is also stated in the university's TM policy where line manager responsibilities are highlighted (Unisa, 2014). "The talent mind-set for line managers" as a theme is significant as is demonstrated in the above discussion. From the findings, it is evident that there is inconsistent understanding of "talent" among line managers. Furthermore, there is a lack of clarity as to how to nurture talent, the roles and responsibilities of line managers across the university, and that of Human Resources require attention. Therefore, the following clarification of roles need to be attended to:

- the specific role of HR as a business partner to line managers in the talent management process;

- the line manager as talent custodian as an important stakeholder;

- the line manager's mind-set needs to shift to one that is driven by talent nurturing and growth and not compliance;

- even though TM is one of the KPAs of all line managers, performance coaching and employee talent optimisation need to be priotitised as key drivers; and

- $\quad$ TM is an integral part of line managers responsibilities and should not be seen as an additional HR process that is bureaucratic in nature.

\section{TM Implementation}

TM implementation that was discussed during the interviews included various strategies as means to implement TM in a targeted manner to address the specific and unique needs that exist at the university. Talent sourcing, development, deployment and retention emerged as sub-themes.

In this regard Meyers et al. (2013) claim that every member of an organisation's workforce is a potential high-performer and highly valuable employee given the right experiences and/or learning opportunities through TM. The ensuing discussion highlights the interventions that may lead to the realisation of talent optimisation.

Talent sourcing. Talent sourcing means an effort to solicit suitable candidates to the institution by employing appropriate and diverse media to ensure that relevant talent aligned with institutional needs is recruited (Collings \& Mellahi, 2009). According to Thunnissen et al., 2013), reaching the correct balance of internal and external talent is important. They further refer to the optimal equilibrium between recruiting on the external labour market and the training and development of internal candidates. Participants stated that "the recruitment process must include competency assessments as a minimum requirement in the selection process." This is supported by the literature where Stahl et al. (2012) indicate that it is important for the organisation to "assess applicants' personalities and values, because formal qualifications may not be the best predictors of performance and retention and that skills are easier to teach or change than personality traits, attitudes and values" (p. 32) The university's ITMS supports the 
literature by including its plan to conduct competency-based interviews and various alternate assessments in addition to the formal interview (Unisa, 2012), even though this is not currently the practice at the university.

A significant issue that participants made reference to was Employment Equity (EE). EE is a national imperative in South Africa with guidelines provided by the Department of Labour. The EE policy is intended to address the imbalances of the country's past racial discriminatory practices and errs. Some participants expressed uncertainty regarding how to apply the EE principles when selecting talent in the interview process and also how this practice would affect the acquisition of the right competencies at the required levels.

Talent development. Talent development was found in the literature to be an area that should be given more attention due to the various perspectives that exist. An example is found in Thunnissen et al. (2013) where they indicate that talented employees should be given special treatment for the purposes of accelerated development. Meyers et al. (2013) argue that TM should focus on experience-based development with on-the-job learning as one of the driving forces of the development process in a costeffective manner.

The aforementioned is aligned with Charles Jennings' 70-20-10 learning strategy where it is argued that $70 \%$ of impactful learning emanates from experience (Jennings, 2013). This is supported by the university's talent interventions, namely; job shadowing, mentorship, accelerated development for young professionals and academics, stretch assignments, communities of practice, leadership development programmes, and various in-house skills development programmes (Unisa, 2012). Participants' perceptions on this sub-theme demonstrate that "although various interventions have been planned in this space, emphasis should be placed on differentiating the investment made in talent in order for return on investment to be realised." An analysis of the university's ITMS revealed that through talent segmentation (Unisa, 2012), differentiated investment is possible; therefore, investment in all categories and levels of employees within the organisation should be made. Literature supports the differentiated investment strategy, where Lewis and Heckman (2006) also have concerns about the high value talent that is found in all spheres of the organisation. This view is echoed by Collings and Mellahi (2009) that "the systematic identification of key positions which differentially contribute to the organisation's sustainable competitive advantage" (p. 304) is necessary. However, Stahl et al. (2012) recommend that the investment in people ought to be limited to the top $10-20 \%$ of the workforce, that is, the most talented and high performing managerial and professional staff. However, this is contrary to the university's stance in the investments it makes in talent.

A challenge that participants expressed was that "the university's policies and strategies do not support us in implementing TM." The term "policy paralysis" was used to summarise the limitations posed on managers to identify, prepare, and mobilise staff members into certain areas. It was also stated that TM may be "creating unrealistic hope because there are few job opportunities for upward mobility." In essence, participants stated that, among others, "employees expect upward mobility soon after they are identified into a talent pool for accelerated or leadership development," therefore, expectations of staff need to be managed sensitively. 
A concept directly related to talent pools and mobility is "succession management" as a key point of departure for engaging employees who show potential and capability. Participants indicated that "the challenge with this talent strategy is that it raises expectations with the identified and qualifying incumbents or talent pool candidates.” The university's ITMS (Unisa, 2012) and TM Policy (Unisa, 2014) support succession management as a key area to sustain and grow the organisation. This is affirmed in the literature by Collings and Mellahi's (2009) evaluation of 40 global companies where it was found that all of them indicated that there was a lack of talent in the pipeline for strategic positions, which considerably inhibited growth and expansion of their business.

Furthermore, Collings and Mellahi (2009) argue that in order for strategic roles to have a significant impact on the organisation's performance, it is essential that those roles are occupied by high performing individuals. However, this is not evident in practice according to the findings of the interviews, where a participant indicated: "We need to engage in succession management to ensure that we have ready talent for various critical positions at any given time, instead of always employing external candidates because we do not develop the capabilities internally." Various participants indicated that "succession management interventions are yet to be implemented in a systematic manner because policies are not clear on the detail relating to succession and the implementation thereof which is a challenge for line managers." Collings and Mellahi (2009) contend that although organisations experience difficulty with the implementation of succession management, it is nonetheless necessary for sustainability and growth.

Another challenge expressed by participants and supported by Welby-Cooke (2010) and Brown (2006) was that "employees do not take ownership of their own career development and depend on line managers to craft a way forward for them." The concept of leadership emerged where a concern was revealed with people in managerial positions who do not have adequate leadership skills and therefore do not encourage people development. Therefore, the need to have an effective and articulated leadership development process for leadership pipelines is critical.

Further limitations expressed by participants were that "the TM strategy lacked clarity"; and "there is a need to define concepts, the purpose, process, and systems used and be clear and consistent on recruitment and promotion criteria." Participants also articulated their concern around the selection of certain staff members to be invested in, which they felt "poses a concern as it tends to create conflict among staff members or with managers as it is not perceived as an all-inclusive process."

Talent deployment and retention. Talent deployment involves internal mobility of employees to ensure that there is person-job fit as well as person-organisation fit. In addition, talent deployment may be determined through psychometric testing provided by the university's HR Organisation Development Directorate as well as the individual's integrated performance management scores.

The practice of "promoting-from-within the organisation" was frequently referred to during the interviews, which encourages upskilling and helps organisations retain talent due to the promotion opportunities and career trajectory that is available. Promoting-from-within also contributes to enhanced performance as well as greater information sharing as it stimulates trust across the various hierarchical levels. This line of thinking is echoed by Lewis and Heckman (2006) where they refer to internal hiring as 
"feeder roles" or as indicated in the university's ITMS "talent pipeline" (Unisa, 2012). Due to the risks that are associated with this policy including the tendency toward insular thinking over time, Stahl et al. (2009), through their research of various companies, have indicated that some companies have resorted to filling $20-30 \%$ of mid-level and senior positions through external recruitment in an attempt to reenergise management teams through bringing into the organisation new perspectives. Participants suggested that "the university should advertise all positions internally first before considering external candidates as an alternative."

Even though the intention to ensure talent mobility (Unisa, 2012) is reflected in the university's ITMS, the current research found that this area of TM is limited to secondments and acting positions and does not address movement of staff to ensure that employees' talents are optimised for the benefit of the individual as well as the organisation. Creating talent pools and highlighting their areas of expertise is ideal in ensuring optimal job-person fit (Lewis \& Heckman, 2006). Participants echoed the findings of the claims found in the literature through, among others, statements such as "talent mobility is critical in ensuring that the organisation does not lose talented individuals but rather that they are mobilised according to their strengths and aspirations."

Another critical area pertaining to the success of the university is retention, which refers to the interventions adopted by the institution that facilitates employees' fulfilled and meaningful employment for a sustained period (Van der Merwe, Basson, and Coetzee, 2009). It includes rewards and recognition strategies, employee benefits, development opportunities, and strategies customised to individual employees. Two important aspects of retention were found to be employee job satisfaction and organisational commitment (Unisa, 2013).

The university has developed a retention framework customised to its context subsequent to an environment scan that was conducted (Unisa, 2013). This is aligned with Israelite's (2010) claim that engagement is a strategy to energise the workforce, which in turn directly impacts the retention rate of the organisation.

Evidently, the challenges pertaining to talent retainment were especially applicable to where scarce skills are required. Participants indicated that "scarce skills are lost because of a lack of latitude and scope for career enhancing strategies available."

\section{Conclusions and Recommendations}

Similar key issues resulting in the main themes that emerged during the qualitative analysis of the indepth interviews were highlighted by the participants. As such, these findings provide an enhanced understanding into the thoughts, feelings, opinions, attitudes, and concerns experienced by Chairs of TM committees in a complex institution. Therefore, the following conclusions and recommendations were compiled.

It is found that a common understanding of the TM concept and mind-set and its aims are not fully shared and applied in the same way by all line managers. Despite uncertainties that exist in the minds of 
line managers, the participants alluded to an overall positive outlook for TM and expressed willingness to participate in the operationalisation of the TM strategy. It is important for the university to be clear in respect of the strategy and approach it chooses to adopt when implementing TM, giving careful consideration to the contextual imperatives.

The research highlights the need for commitment from senior management and line managers, with HR playing a critical role in strategic engagements such as communication and consultation with key stakeholders. In the absence of stakeholder engagements, ownership will be deficient or non-existent and failure of investment in TM will be imminent. Strong commitment to leadership development is a critical aspect of the success of TM within an organisation. This should be given priority as it has a ripple effect on employee engagement which affects the overall functioning of the university.

It is evident that a holistic approach must be taken regarding the implementation of talent interventions. The priority is that talent attraction, development, deployment and retention strategies, and interventions should be integrated. In addition, a pluralistic view to TM must be taken whereby "a one-size fits all" approach must not be applied. Differentiation and segmentation of talent is important to ensure fairness and equitable investment in the workforce.

It is also clear that all related human resources policies must support the intentions of TM and if these are not in place, a review of policies should be called for to assess and rectify, if necessary, the core foundation before the implementation of TM interventions.

The findings further showed that succession management is necessary but no evidence exists that this is indeed in place and practiced at the university. To ensure its success, fairness and transparency must be exercised and employee expectations must be managed, so as to ensure that the good intention is not counteracted by negative perceptions.

Since a promote-from-within policy may not always be possible due to policy and governance restrictions, an alternative practice of advertising all positions internally first was a strong recommendation made by participants. The study also concluded that not all managers who are appointed possess a talent mind-set. It is the responsibility of HR to build this mind-set through ongoing leadership and management capacitation programmes to ensure that all staff is given appropriate opportunities for development and career acceleration.

The issue around talent sourcing as it relates to South Africa's national imperatives on EE arose during this study and provocative statements and sentiments were shared among many of the participants. This strengthens the need for line managers to understand the concept of diversity and how recruitment practices ought to be conducted to ensure fairness, while addressing the national transformation agenda.

The conclusion around the retention of individuals with scarce skills is that a choice is made when joining an organisation. Benefits beyond counter salary offers should be considered to retain such individuals. It is the responsibility of the line manager to support talent management and to use the various interventions in managing employees to ensure optimal benefit by the individual and the organisation.

A final conclusion is that although TM had been introduced at the university, its implementation and the 
value-add measure could not be fully realised to date but that adequate evidence exists that a mind shift has occurred among line managers and specifically Chairs of TM committees towards a new narrative about the value and contribution of talent management at the university. It is concluded that Unisa as an ODL institution has not completely shifted towards providing talent for its current and future operational requirements. Contributing to the bottom line in an ODL environment means getting talent ready for a different educational landscape; one that is agile and flexible enough to respond to the needs of the student and environmental factors. In essence, the inclusive TM approach has been adopted by Unisa, albeit that its significance may not yet be fully appreciated due to the gap experienced in its implementation which is in process of being operationalised.

It is recommended that the TM strategy implementation plan be reviewed to include suggestions as discussed above. Dunlop, Firth, and Lurie (2013) emphasise the following key actions whenever strategy implementation is considered, namely; "ensure that the strategy translates into action, adapt the strategy and policies when required, and ensure that the required processes and systems are institutionalised to sustain the strategy" ( $\mathrm{p} 4$ ). It is further recommended that line managers be made aware of the "organisational social context factors such as organisational culture, politics, climate and social interactions" (Sikora \& Ferris, 2014, p. 279) which plays an important role and could influence their decision making and TM implementation strategies.

This study had limited scope in respect of the interviewees where only line managers were interviewed and not the talent pool candidates. Another limitation was that implementation had not begun in a systematic way at the time of the study being conducted as plans for implementation were yet to be set in motion.

Further research needs to be done on how to systematically implement TM in an organisation, but the various factors discussed in this article must also be supported by policy and strategy to facilitate a more targeted change management and implementation plan of TM initiatives. Further research is warranted in the areas of identifying and engaging talent due to the significant impact these areas have on the organisation. It is also recommended that further research should be conducted on the potential impact of TM if applied to the highest levels of the organisation's leadership as well as the outcomes and return on investment of talent development efforts.

\section{References}

Al, A., Cascio, W. F., \& Paauwe, J. (2014). Talent management: Current theories and future research directions. Journal of World Business, 49(2), 173-179.

Amidon, S.R. (2005). Writing the LO. Business Communication Quarterly, 68(4), 406-428.

Ashton C, \& Morton L. (2005). Managing talent for competitive advantage: Taking a systemic approach to talent management. Strategic HR Review, 4(5), 28-31.

Bradley, A. P. (2016). Talent management for universities Australian universities ' review. 58(1), 13-19. 
Retrieved from http://files.eric.ed.gov/fulltext/EJ1091199.pdf

Brown, R.B. (2006). Doing your dissertation in business and management: The reality of research and writing. Oxford: Sage Publications.

Cappelli P., \& Keller, J.R. (2014). Talent management: Conceptual approaches and practical challenges. Annual Review of Organizational Psychology and Organizational Behavior, 1, 305-31.

Collings, D.G., \& Mellahi, K. (2009). Strategic talent management: A review and research agenda. Human Resource Management Review, 19, 304-313.

Dunlop, A., Firth, V., \& Lurie, R. (2013). Dynamic strategy implementation: Delivering on your strategic ambition. Deloitte: Deloitte University Press. Retrieved from http://www2.deloitte.com/content/dam/Deloitte/za/Documents/strategy/ZA ThoughtLeadership Updated.pdf

Gallardo-Gallardo, E., Dries, N., \& González-Cruz, T. F. (2013). What is the meaning of "talent" in the world of work? Human Resource Management Review, 23(4), 290-300.

Galagan, P. (2008). Talent management: What is it, who owns it, and why should you care? Talent Development , 62, 40-44.

Harter, J.K., Schmidt, F.L., \& Keyes, C.L. (2002). Well-Being in the workplace and its relationship to business outcomes: A review of the gallup studies. In C.L. Keyes, \& J. Haidt (Eds.), Flourishing: The positive person and the good life (pp. 205-224). Washington, DC: American Psychological Association.

Israelite, L. (2010). Thinking about talent. In L. Israelite (Ed.), Talent management: strategies for success from six leading companies (pp. 1-14).Virginia: ASTD Press.

Jennings, C. (2013, June, 24). 70:20:10 - A framework for high performance development practices [Blog post]. Retrieved from http://charles-jennings.blogspot.co.za/2013/06/702010-framework-forhigh-performance.html

Lewis, R.E., \& Heckman, R.J. (2006). Talent management: A critical review. Human Resource Management Review, 16, 139-154.

McDonnel, A. (2011). Still fighting the 'war for talent'? Bridging the science versus practice gap. Journal of Business and Psychology, 26(2), 169-173.

Mellahi, K., \& Collings, D.G. (2010). The barriers to effective global talent management: The example of corporate e' lites in MNEs. Journal of World Business, 4, 143-149.

Mercy, M. (2011). Retaining Africa's talent: The role of Africa's higher education. International Journal of Emerging Markets, 6(2), 168-179. 
Metcalf, H., Rolfe, H., Stevens P., \& Weale M. (2005). Recruitment and retention of academic staff in higher education national institute of economic and social research. National Institute of Economic and Social Research. Department for Education and Skills, Research Report RR658. Retrieved from www.dfespublications.gov.uk

Meyers, M.C., Van Woerkom, M., \& Dries, N. (2013). Talent - innate or acquired? Theoretical considerations and their implications for talent management. Human Resource Management Review, 23, 305-321.

Meyers, M.C., \& Van Woerkom, M. (2014). The influence of underlying philosophies on talent management: theory, implications for practice and research agenda. Journal of World Business, 49, 192-203.

Mkhize P., Mtsweni S., \& Buthelezi P. (2016). Diffusion of innovations approach to the evaluation of learning management system usage in an open distance learning institution. International Review of Research in Open and Distributed Learning, 17(3), 296-312.

Mishra, S. (2008). The talent powered organisation: strategies for globalisation, talent management and high performance. Talent Development, 62(1), 80-81.

Ramdass K, \& Masithulela F. (2016). Comparative analysis of pedagogical strategies across disciplines in open distance learning at Unisa. International Review of Research in Open and Distributed Learning, 17(2), 1-18.

Rosenthal, R. (1973). The Pygmalion effect lives. Psychology Today, 7(4), 56-63.

Schiemann, W.A. (2014). From talent management to talent optimisation. Journal of World Business, 49, 281-288.

Stahl, G., Bjorkman, I., Farndale, E., Morris, S.S., Paauwe, J., Stiles, P., ... Wright, P. (2012). Six principles of effective global talent management. Sloan Management Review, 53(2), 25-42.|

Sikora, D.M., \& Ferris, G.R. (2014). Strategic human resource practice implementation: The critical role of line management. Human Resource Management Review, 24, 271-281.

Thunnissen, M. (2016). Talent management: For what, how and how well? An empirical exploration of talent management in practice. Employee Relations, 38(1), 57-72.

Thunnissen, M., Boselie, P., \& Fruytier, B. (2013). Talent management and the relevance of context: Towards a pluralistic approach. Human Resource Management Review, 23(4), 326-336.

Thunnissen, M., Boselie, P., \& Fruytier, B. (2015). A review of talent management: 'Infancy or adolescence?' The International Journal of Human Resource Management, 24(9), 1744-1761.

Unisa. (2012). Integrated talent management strategy [Strategy]. Retrieved from http://staffcmsys.unisa.ac.za/cmsys/staff/contents/departments/hr/hrd/tmanage/docs/Integrat 
ed TM Strategy.doc

Unisa. (2014). Unisa talent management policy [Policy]. Retrieved from http://staffcmsys.unisa.ac.za/cmsys/staff/contents/departments/hr_policies/docs/Policy\%20\%20Talent\%20Management\%20-\%20appr\%20Council\%20-\%2019.09.2014.pdf

Unisa. (2016). The leading ODL university. Retrieved from http://unisa.ac.za/sites/corporate/default/About/The-leading-ODL-university

Van den Brink, M., Fruytier, B., \& Thunnissen, M. (2013). Talent management in academia: Performance systems and HRM policies. Human Resource Management Journal, 23(2), 180-195.

Van der Merwe, W., Basson, J.S., \& Coetzee, M. (2009). Non-financial recognition: Exploring employees' preferences in a South African information technology organisation. SA Journal of Labour Relations, 33(2), 75-99.

Welby-Cooke, G. (2010). The psychometric properties of a talent mind-set index (Master's Thesis, University of Pretoria, Pretoria. Retrieved from http://hdl.handle.net/2263/29273 